\title{
Differences in Return of Spontaneous Circulation in Early vs Late Endotracheal Intubation among Patients in Hospital Cardiac Arrest
}

Battu Kumar Shrestha , ${ }^{1}$ Apurb Sharma, ${ }^{1}$ Parbesh Kumar Gyawali ${ }^{1}$

${ }^{1}$ Shahid Gangalal National Heart Centre, Kathmandu, Nepal.

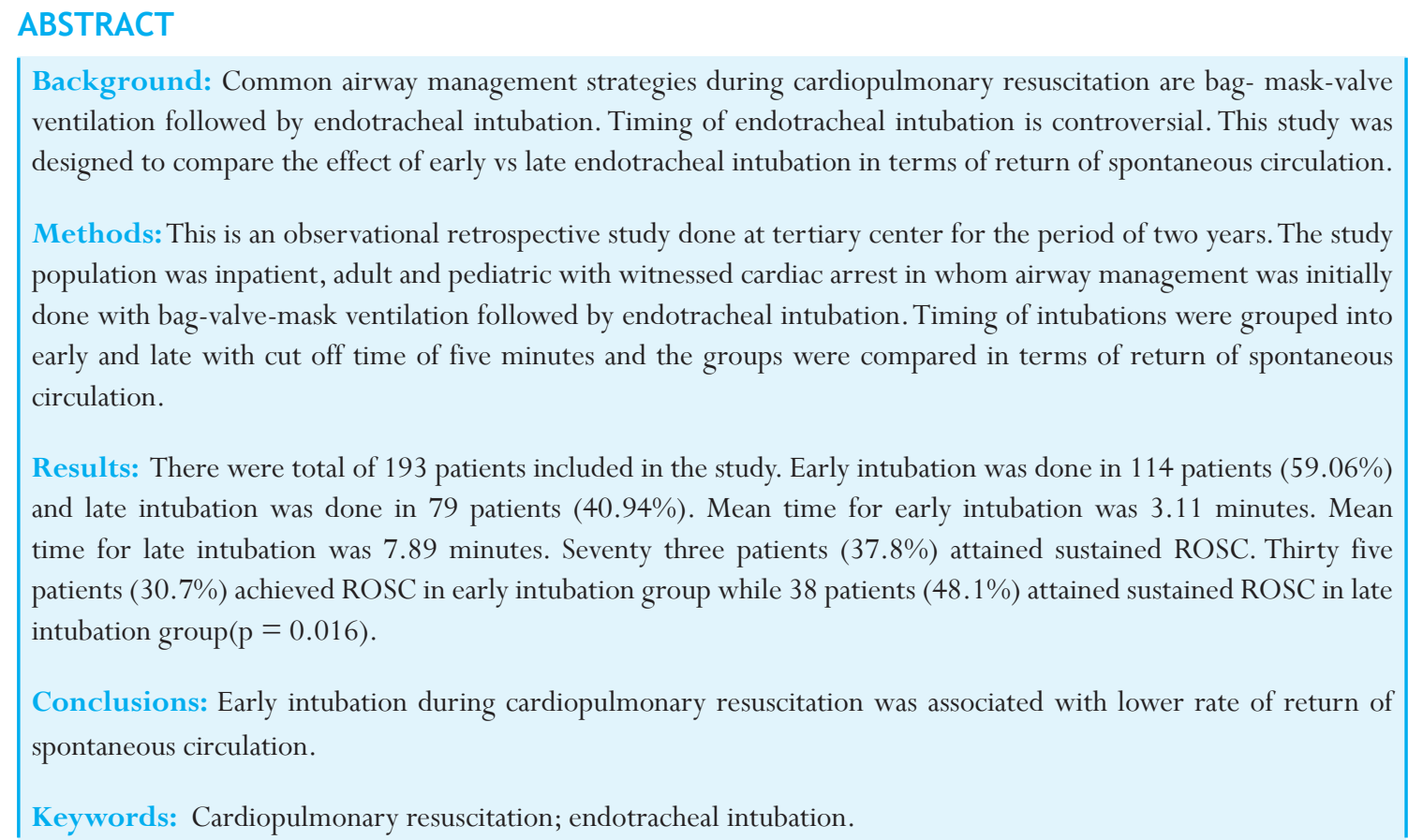

\section{INTRODUCTION}

Airway management is the essential component of cardiopulmonary resuscitation (CPR). Different airway management strategies such as bag-valve-mask ventilation, endotracheal tube, supraglotic airway devices have been recommended. ${ }^{1,2}$ Optimal ventilation management is crucial for high quality CPR. Traditional concepts of airway management during cardiac arrest includes opening of airway, delivering of $100 \%$ oxygen and early tracheal intubation. We expect that intubation protects airway, prevents aspiration, provides adequate oxygenation and wash out carbondioxide more efficiently. However, hyperventilation along with intermittent positive pressure ventilation may have negative effect on return of spontaneous circulation. ${ }^{3}$ Optimal timing for endotracheal intubation during the time of cardiac arrest has not been established. Moreover, airway management strategy and outcome of in hospital cardiac arrest patients from low and middle income country are scarce. The data from the specialized cardiac center is unavailable. The objective of this study was to identify the effect of early and late endotracheal intubation during the time of cardiac arrest in terms of return of spontaneous circulation.

\section{METHODS}

This was a retrospective observational study carried out in Shahid Gangalal National Heart Center, a tertiary level cardiac center of Nepal from July 2012 to July 2014. The methodology was approved by institutional review committee of this center. All the data were retrieved from the form filled by on duty staff nurse in a preformed sheet in the hospital records especially used for CPR. Patients with undetectable vitals during Emergency visit were excluded. Patients who had "do not attempt resuscitation" order were also excluded. All the patient in the study were witnessed cardiac 
arrest among inpatients. Early endotracheal intubation was defined as intubation done within five minutes or earlier. Late intubation was defined as those intubations done after five minutes. Primary outcome measure was sustained return of spontaneous circulation for more than twenty minutes. Cut off time of twenty minutes for sustained return of spontaneous circulation was taken from recommended guidelines for reviewing, reporting and conducting research on inhospital resuscitation. ${ }^{6}$

All the data collected were entered into Microsoft Excel 2010. Data was analyzed by means of statistical software SPSS 20 and with categorical variables were analyzed with Chi Square or Fischer Exact test. The 2-sided $\mathrm{p}$-value less than 0.05 was taken as significant.

\section{RESULTS}

There were total number of 14,201 patients admitted from July 2012 to July 2014. Among them cardiac arrest were witnessed in 193 which were patients included for the study. Table 1 shows the different variables compared with respect to return of spontaneous circulation, the primary outcome. Airway management was done with bag-valve-mask ventilation at the beginning and later intubated with endotracheal tube. Cardiopulmonary resuscitation was continued for one hour. Mean time for intubation was 5.07 minutes. Seventy three patients (37.8\%) achieved return of spontaneous circulation. Early intubation was done in 114 patients (59.06\%) and late intubation was done in 79 patients (40.94\%). Mean time for early intubation was 3.11 minutes. Mean time for late intubation was 7.89 minutes. Thirty five patients achieved ROSC in early intubation group while 38 patients attained sustained ROSC in late intubation group which was statistically significant $(p=0.016)$ (table 2).

All patients were monitored with ECG and SPO2. Non invasive BP monitoring was done in $72.5 \%$ of patients $(n=140)$ while invasive BP monitoring was present in $27.5 \%$ of patients $(n=53)$. End tidal monitoring was done in none of the patients.

\begin{tabular}{|c|c|c|c|c|}
\hline Variable & & Total CPR & ROSC & p \\
\hline \multirow[t]{2}{*}{ Age } & $<14$ years & 36 & 12 & \multirow[t]{2}{*}{0.57} \\
\hline & $>14$ years & 157 & 61 & \\
\hline \multirow[t]{2}{*}{ Sex } & Male & 117 & 41 & \multirow[t]{2}{*}{0.36} \\
\hline & Female & 76 & 32 & \\
\hline
\end{tabular}

\begin{tabular}{|c|c|c|c|c|}
\hline \multirow[t]{3}{*}{ Diagnosis } & $\mathrm{CHD}$ & 28 & 9 & \multirow[t]{3}{*}{0.44} \\
\hline & VHD & 134 & 4 & \\
\hline & IHD & 31 & 15 & \\
\hline \multirow[t]{5}{*}{ Locations } & ER & 71 & 37 & \multirow{5}{*}{0.002} \\
\hline & CCU/MICU & 54 & 10 & \\
\hline & GW & 11 & 3 & \\
\hline & SICU & 46 & & \\
\hline & CATH & 11 & 5 & \\
\hline \multirow{3}{*}{$\begin{array}{l}\text { Rhythm at } \\
\text { the time } \\
\text { of cardiac } \\
\text { arrest }\end{array}$} & Bradycardia & 45 & 18 & \multirow[t]{3}{*}{0.72} \\
\hline & Asystole & 65 & 22 & \\
\hline & $\mathrm{VT} / \mathrm{VF}$ & 83 & 33 & \\
\hline \multirow{4}{*}{$\begin{array}{l}\text { CPR } \\
\text { attended } \\
\text { by }\end{array}$} & Nurses & 10 & 7 & \multirow[t]{4}{*}{0.12} \\
\hline & $\begin{array}{l}\text { Medical } \\
\text { officer }\end{array}$ & 11 & 5 & \\
\hline & Specialist & 8 & 4 & \\
\hline & Team & 164 & 57 & \\
\hline \multirow{3}{*}{$\begin{array}{l}\text { Start of } \\
\text { CPR }\end{array}$} & $<1 \min$ & 178 & 67 & \multirow[t]{3}{*}{0.68} \\
\hline & 1 to $5 \mathrm{~min}$ & 14 & 6 & \\
\hline & $>5 \min$ & & 0 & \\
\hline
\end{tabular}

\begin{tabular}{llrrr}
$\begin{array}{llrl}\text { Duration } \\
\text { of CPR }\end{array}$ & $<10 \mathrm{~min}$ & 13 & 10 & 0.00 \\
& $10-30 \mathrm{~min}$ & 146 & 59 & \\
& $>30 \mathrm{~min}$ & 34 & 4 & \\
\hline
\end{tabular}

$C H D=$ Congenital Heart Disease, $V H D=$ Valvular Heart Disease, $I H D=$ Ischemic Heart Disease, $E R=$ Emergency Room, $C C U$ = Coronary Care Unit, MICU = Medical Intensive care Unit, $G W=$ General Ward, SICU = Surgical Intensive Care Unit)

\begin{tabular}{lllr}
\multicolumn{4}{l}{ Table 2. Early vs late intubation. } \\
Intubation & Total & ROSC & P value \\
\hline Early & $114(59.06 \%)$ & $35(47.94 \%)$ & 0.016 \\
Late & $79(40.93 \%)$ & $38(52.05 \%)$ & \\
Total & 193 & 73 & \\
\hline
\end{tabular}

\section{DISCUSSION}

The recent resuscitation guidelines recommends uninterrupted chest compression during cardiac arrest. ${ }^{4,5}$ However, placement of invasive airway gets the priority. In our study, the percentage of early tracheal intubation was $59.06 \%$. Every resuscitator may not be expert in invasive airway placement. This may result in increase in number of attempts for intubation leading to airway injuries. Undetected misplacement of the tube into esophagus increases intra-abdominal pressure which increases the aspiration of gastric contents. All these events results in interruptions of chest compression. 
This observational study is carried out in tertiary cardiac center of Nepal to find out whether our current practice is improving or decreasing the patient outcome.

The cut off time for early and late intubation was based on the National registry of Cardiopulmonay Resuscitation (NRCPR) Scientific Advisory Board recommendations for placement of invasive airway within five minutes..$^{6,7}$ Wong et al carried out an observational study with five minutes as a cut off time to see the effect on resuscitation outcome with early and late invasive airway. ${ }^{8}$ The study of Wong et al was done with different invasive airways like endotracheal intubation, laryngeal mask airway, tracheostomy or cricothyroidectomy. The patients population was adult with age more than eighteen years, both cardiac and non cardiac problem. Our study was carried out in only cardiac patients of all ages and intubated with endotracheal intubation. All our cardiac arrests were witnessed. We have only one primary outcome as return of spontaneous circulation. This is because we have inadequate data regarding hospital discharge due inadequate patient profile in resuscitation form. Our finding was similar to the finding of Wong et al that late invasive airway results in better outcome as compare to early intervention.

Endotracheal intubation has many advantages such as it provides adequate ventilation, delivers high inspired oxygen concentration and prevents aspiration of gastric contents. In contrary to that, endotracheal intubation along with positive pressure ventilation may have negative effects in outcome of resuscitation. This is due to increase in intrathoracic pressure, decrease in venous return and cardiac output and thus decrease the coronary perfusion pressure. ${ }^{3,9}$ Studies have shown that early tracheal intubation does not improve the outcome of cardiopulmonary resuscitation. ${ }^{10,11,12} \mathrm{So}$ it is the time for us to have a clear idea about optimal airway management during the time of arrest.

Airway management during cardiopulmonary resuscitation may be basic and advanced. Basic airway management includes triple maneuver, bag-valvemask ventilation or insertion of oropharyngeal or nasopharyngeal airway. Advanced airway management includes insertion of supraglotic airway devices, tracheal intubation, insertion of combitube or cricothyroidectomy. Hanif et al found in their study that bag-valve-mask ventilation if performed adequately may be enough in most of the situation. ${ }^{10}$ These patients do not require advanced airway at al. Supraglotic airways are more easier to insert than endotracheal intubation. However a recent study showed worse outcome when supraglotic airways were compared with endotracheal intubation. ${ }^{13}$ CARES study (Cardiac Arrest Registry to Enhance Survival) also showed similar result. ${ }^{14}$ Bobrow et al found a significant improvement in survival of out of hospital cardiac arrest with minimally interrupted CPR with delayed endotracheal intubation. ${ }^{15}$ However study of Bobrow et al and other guidelines do not provide clear idea about the placement time of invasive airway. Study by Anderson and colleagues also do not support for early tracheal intubation in adult in-hospital cardiac arrest. ${ }^{16}$

Because of inadequate data recording, we cannot analyze the other variable of patient outcome especially hospital discharge, who performed the intubation and number of attempts.

\section{CONCLUSIONS}

The established importance of high quality chest compression and early defibrillation should not be interrupted in an attempt to intubate the patient in early phase of resuscitation. Intubation can be done in later phase of resuscitation with adequate planning with expert hand so that it take shortest possible time and attempt with minimal interruption of chest compression.

\section{REFERENCES}

1. Nolan JP, Soar J. Airway techniques and ventilation strategies. Current Opin Crit Care. 2008;14(3):279-86. [Full Text]

2. Kurola J, Harve H, Kettunen T, Laakso JP, Gorski J, Paakkonen H, Silfvast T. Airway management in cardiac arrest-comparison of the laryngeal tube, tracheal intubation and bag-valve mask ventilation in emergency medical training. Resuscitation.2004;61(2):149-53. [Science Direct]

3. Aufderheide TP, Sigurdsson G, Pirrallo RG, Yannopoulos D, McKnite S, von Briesen C, Sparks CW, Conrad CJ, Provo TA, Lurie KG. Hyperventilation-induced hypotension during cardiopulmonary resuscitation. Circulation. 2004;109:1960-65.[Full Text]

4. Soar J, Nolanb J, Böttiger B, Perkins G, Lott C, Carli P, Pellis T, Sandroni C et al. European Resuscitation Council Guidelines for Resuscitation 2015 Section 3. Adult advanced life support. Resuscitation 2015;95:100-147.

5. Neumar R, Shuster M, Callaway C, Gent L, Atkins D, 
Bhanji F, Brooks S et al. Part 1: Executive summary: 2015 American Heart Association guidelines update for cardiopulmonary resuscitation and emergency cardiovascular care. Circulation. 2015;132:S315-S367.

6. Cummins RO, Chamberlain D, Hazinski MF, Nadkarni V, Kloeck W, Kramer E, et al. Recommended guidelines for reviewing, reporting, and conducting research on inhospital resuscitation: the in-hospital 'Utstein Style': a statement for healthcare professionals from the American Heart Association, the European Resuscitation Council, the Heart and Stroke Foundation of Canada, the Australian Resuscitation Council, and the Resuscitation Councils of Southern Africa. Circulation. 1997;95:2213-39.

7. National Registry of Cardiopulmonary Resuscitation Scientific Advisory Board. Best evidence available for gold standard process variables and process of care exceptions; 2004.

8. Wong ML, CareyS,Mader TJ and Wang H. Time to invasive airway placement and resuscitation outcomes after inhospital cardiopulmonary arrest. Resuscitation. 2010;81: 182-86. [Schience Direct]

9. Pitts S and Kellermann AL. Hyperventilation during cardiac arrest. The Lancet. 2004;364:313-15.[Science Direct]

10. Hanif MA, Kaji AH, Niemann JT. Advanced airway management does not improve outcome of out-of-hospital cardiac arrest. Acad Emerg Med. 2010;17:926-931.[Full Text]
11. McMullan J, Gerecht R, Bonomo J, Robb R, McNally B, Donnelly J, Wang HE and CARES Surveillance Group. Airway management and out-of-hospital cardiac arrest outcome in the CARES registry. Resuscitation. 2014;85(5):617-22[Science Direct]

12. Shin SD, Ahn KO, Song KJ, Park CB, and Lee EJ. Out of hospital airway management and cardiac arrest outcomes: a propensity score matched analysis. Resuscitation. 2012;83: 313-319[Science Direct]

13. Wang HE, Szydlo D, Stouffer JA, Lin S, Carlson JN, Vaillancourt C, Sears G, Verbeek RP, Fowler R, Idris AH, Koenig K. Endotracheal intubation versus supraglottic airway insertion in out-of-hospital cardiac arrest. Resuscitation. 2012;83(9):1061-6.[Science Direct]

14. McMullan J, Gerecht R, Bonomo J, Robb R, McNally B, Donnelly J, et al. Airway management and out-ofhospital cardiac arrest outcome in the CARES registry. Resuscitation. 2014;357:617-22.[Science Direct]

15. Bobrow BJ, Clark LL, Ewy GA, Chikani V, Sanders AB, Berg RA, et al. Minimally interrupted cardiac resuscitation by emergency medical services for out-of-hospital cardiac arrest. JAMA. 2008;299:1158-1165.[Full Text]

16. Andersen LW, Granfeldt A, Callaway CW, Bradley SM, Soar J, Nolan JP, et al. Association between tracheal intubation during adult in-hospital cardiac arrest and survival. JAMA. 2017;317 95):494-506. Full Text] 